\title{
Emergency Medical Consequence Planning and Management for National Special Security Events After September 11: Boston 2004
}

\author{
Phillip L. Coule, MD, Richard B. Schwartz, MD, and Raymond Swienton, MD
}

$\mathrm{M}$ ass gatherings such as political conventions, sporting events, festivals, and parades are a common occurrence throughout the United States, yet only sparse literature exists on the regional coordination and analysis of such events. That is why Kade and colleagues are to be commended for attempting to provide some analytical benchmarks and affording us the opportunity to review consequence management for mass gatherings. The labeling of this particular event as a national special security event (NSSE) sets the alert bar high as it highlights unique challenges and opportunities presented when supporting an event predesignated as one of national importance. Some generalizable qualities of the article include medical treatment, regional coordination, and regional surge capacity.

Medical treatment is a difficult topic because standard definitions of different types of event are lacking. These include outcome measures such as utilization rates and illness composition. The National Association of Emergency Medical Services (EMS) Physicians published a position paper that highlighted the disparity of standards and patient encounters. ${ }^{1}$ In this issue of Disaster Medicine and Public Health Preparedness, Kade et al report a patient utilization rate of 11.6 patients per 1000 attendees. Previous reports of mass gathering medical care have been as low as 0.25 patients per 1000 attendees $^{2}$; however, no standard case definition exists for encounters with the medical team to allow full comparisons. The differences of such a broad utilization rate make planning difficult because these numbers represent a 46-fold difference span. Perron et al reported a strong association between the heat index and utilization rates, with 3 additional individuals seeking care for every $10^{\circ}$ increase in the heat index. ${ }^{3}$ Perron and coworkers also reported a lack of critical patients for this event, a common theme in reports regarding mass gathering events. The report of a lack of critical patients at mass gathering events should not dissuade others using this report as a framework for their planning from considering and planning for critical patients because they could be faced with a significantly different utilization rate, as described above. In particular, papal visits and sporting events have a higher incidence of cardiac arrest when compared with other mass gathering event types. ${ }^{4}$ Unpublished data from the medical coverage of a large, wellattended professional golf tournament in the southeastern United States reveals a utilization rate of 1.63 patients per 1000 attendees, with 3\% of all patient encounters requiring transport to the emergency department (unpublished data, patient database of the Medical College of Georgia Center of Operational Medicine Event Medicine Team, May 6, 2008). It is likely that heat index, access to water, age of attendees, "event stress," and the consumption of alcoholic beverages are the significant variables that contribute to the utilization rate for medical services at a mass gathering. Medical problems such as dehydration and access to water are highlighted. Dehydration is expected as a common complaint at an outdoor event in the summer, but not at an indoor political convention; a surprising occurrence.

Medical treatment for vulnerable populations such as children, pregnant women, and older adults is also lacking because mass gatherings attract large numbers of diverse individuals. Kade et al highlight the unanticipated encounter rate with pediatric patients during the 2004 Democratic National Convention (DNC), which should provide guidance to planners that, regardless of the focus or demographic makeup of the expected attendees, vulnerable populations such as children must always be considered. The identification of other vulnerable and special needs populations during mass gatherings is also warranted.

Kade et al also analyzed regional EMS coordination and demonstrated the value of mutual aid agreements. During the DNC, private sector partners responded to approximately $25 \%$ of the call volume for the week of the meeting (they typically respond to $<1 \%$ ). This could be cause for alarm because citywide response times to increase would be expected to increase; however, priority 1,2 , and 3 calls remained relatively the same as compared with a typical week. 
This suggests a significant amount of preplanning and coordination with the private sector. Interpretation of this observation would be enhanced by additional data on EMS call volumes, mutual aid staging locations and EMS dispatch prioritization of these mutual aid resources, and local hospital emergency department bed volume. This information would allow for analysis of the entire health care system, not simply medical care delivered at the scene.

Kade et al described the roles of the executive committee and medical advisory group in the planning and execution of event coverage. Although the makeup of the committee is comprehensive, potential problems in medical response could occur if the medical assets of federal partners responsible for crisis management are not included in the medical planning process. Presidential Decision Directives 39 and 62 designate the Federal Bureau of Investigation (FBI) as the lead agency for crisis management and the Federal Emergency Management Agency as the lead agency for consequence management. Although the Federal Emergency Management Agency was included in the Medical Advisory Group (MAG) planning for the event, it appears that the FBI was not; therefore, it is not evident whether the medical assets of the FBI were fully informed and integrated into the medical plan. Another potential problem that may have been addressed by the MAG but not expressly stated in the article is tactical emergency medical support (TEMS). In the event of a terrorist attack, TEMS support will be vital, and integration of the TEMS assets in conventional prestaged medical assets is critical. In addition, it is important to consider all stakeholder local or region-specific agencies and entities in strategic planning for mass gatherings.

Kade et al also highlight the importance of surge capacity. Being locally prepared for a mass gathering event requires the acquisition of substantial resources from regional and national sources. ${ }^{5}$ The article notes difficulties in dealing with federal agencies when requesting and receiving caches of supplies and equipment. These difficulties are not unique to an NSSE and foreshadowed the difficulties that were experienced in receiving medical supplies and caches in the response to Hurricane Katrina. The authors also describe what appears to be a well-designed plan to provide decontamination and antidotes to victims of a chemical or biological event. The importance of a network of locations from which to distribute mass prophylaxis and to stockpile antidotes cannot be overstated. The lesson identified here is not in the quantity or selection of items for the specific event; rather, it is that each municipality in which substantial mass gatherings occur is able to procure the equipment and supplies in a timely manner to ensure local preparedness.
The importance of education and continued training was also emphasized by Kade and colleagues. The role of local, regional, and nationally standardized competency-based education and training programs in disaster medicine and public health preparedness is vital to mass gathering preparedness or any potential mass casualty event. The challenges in maintaining such educational programs are many. The benefits in preparedness clearly outweigh the challenges in achieving educational and maintaining training objectives.

In summary, Kade et al have contributed to the growing body of knowledge concerning the medical coverage of mass gatherings. NSSEs are a uniquely difficult type of mass gathering, with additional security measures complicating most aspects of a medical plan. Political conventions are potentially highprofile targets for terrorists, making medical coverage planning and mass casualty incident planning critical to an event. The article should also serve to encourage future contributions to the discipline of disaster medicine and public health preparedness, and to spotlight the difficult challenge of advancing the methods applied to capturing meaningful observations and data elements in the experience of actual events.

\section{About the Authors}

Dr Coule is Director, Center for Operational Medicine, and Dr Schwartz is Chair, Department of Emergency Medicine, Medical College of Georgia. Dr Swienton is Co-Director of Emergency Medical Services, Disaster Medicine and Homeland Security Section, University of Texas Southwestern Medical Center.

Address correspondence and reprint requests to Dr Philip L. Coule, Department of Emergency Medicine, School of Medicine, Medical College of Georgia, AF-2036, 1120 15th St, Augusta, GA 30912 (e-mail: pcoule@mcg.edu).

Received for publication August 7, 2008; accepted August 8, 2008.

\section{Authors' Disclosures}

The authors report no conflicts of interest.

ISSN: 1935-7893 (C) 2008 by the American Medical Association and Lippincott Williams \& Wilkins.

\section{DOI: 10.1097/DMP.0b013e318189a714}

\section{REFERENCES}

1. Jaslow D, Yancy A 2nd, Milsten A. Mass gathering medical care. National Association of EMS Physicians Standards and Clinical Practice Committee. Prehosp Emerg Care. 2000;4:359-360.

2. Morimura N, Takahashi K, Katsumi A, et al. Mass gathering medicine for the First East Asian Football Championship and the 24th European/ South American Cup in Japan. Eur J Emerg Med. 2007;14:115-117.

3. Perron AD, Brady WJ, Custalow CB, Johnson DM. Association of heat index and patient volume at a mass gathering event. Prehosp Emerg Care. 2005;9:49-52.

4. Michael JA, Barbera JA. Mass gathering medical care: a twenty-five year review. Prehosp Disaster Med. 1997;12:305-312.

5. Auf der Heide E. The importance of evidence-based disaster planning. Ann Emerg Med. 2006;47:34-49. 